ceiling when fire breaks out. This breaks a closed electric circuit, and an electrical relay at once starts a clockwork motor. The motor drives a small dialling drum, the small metal discs on which correspond to the letters and figures of the telephone number of the nearest fire station. The station is thus called up and a gramophone record then comes into action giving, in a verbal message, the location of the fire and all essential details. This message is repeated continuously for $3 \frac{1}{2}$ minutes. If necessary, also, it can be made to ring up a second number-for example, that of the owner of the building-and repeat its message. When used as a burglar alarm, the signaphone is connected with an electric circuit in the building. In this case, a burglar who opens a door or window, takes down a picture or tries to open a safe or desk, without knowing it thereby summons the police, who learn from the the gramophone message what is happening. Anyone who desires to have both a fire and burglar alarm must have two signaphones installed. The Post Office has given permission for these devices to be attached to telephones on automatic exchanges. It has also met with the approval of the Metropolitan Police, to whom it has been demonstrated.

\section{Equalising Supply and Demand}

IN the first number of Trends-A Monthly Graphical Review of Business Movements (H. Whitehead and Staff, 20 Buckingham Gate, S.W.1, October 1935), Mr. Harold Macmillan contributes an interesting article on "Equalising Supply and Demand" in which he emphasises the importance of planning an adjustment of productive effort, so as to ensure the production of all goods and services in the quantities which will enable them to exchange for one another at prices covering their production costs. The regulation of production in relation to demand for the products of each industry requires that some common policy should be pursued by all the units collectively, for example, in regard to scientific research, observance of standard wages and conditions, maintenance of standards of quality or standardisation of the range of patterns. But as things are, a common policy must depend on voluntary agreements, and in the great majority of cases voluntary agreements break down because, when they have created conditions of stability and profit. ability, other producers are attracted who can exploit the market by the old methods. Mr. Macmillan therefore urges that it is necessary to give industry legal powers to enforce upon a recalcitrant minority decisions which have been approved by a large majority of the producers and have been sanctioned by Parliament. It is essential, however, that there should be adequate safeguards to defend the general public interest and the special interests of consumers and workers affected in each case.

\section{Despotic and Democratic Governments}

THE question as to whether parliamentary democracy can survive its present crisis and whether the rise of dictatorships in Italy, Germany and Russia does not indicate the decline of a long epoch of parliamentary government, is discussed by $\mathrm{Mr}$. Herbert W. Stewart in an article in the Hibbert Journal (April, 1935). Mr. Stewart definitely rejects the modern scepticism, although he is far from denying many of the difficulties and real dangers involved in the parliamentary system, such as party intrigues, the corruption of the free but corruptible Press, the demagogic misuse of public institutions under parliamentary control. The unavoidable dilemma of this system seems to be that current affairs are run either by expert commissions, more or less on account of the initiative of the electorate and its parliamentary representatives-or by the masses themselves, and this involves the danger of delicate political matters becoming dependent on the issue of demagogical party activities and political bargainings.

ComparIng these dangers with those of Fascist States, however, Mr. Stewart concludes that Fascist State policy is apt to replace a comparative evil by a much more radical one ; for an oligarchy controlling the key positions of the State is worse than the personal power of local cliques under parliamentary government. Parliamentary corruption is the smaller evil as compared with the possible and hidden corruption under a despotic government. The disadvantages of democratic governments should not be over-stressed. In the United States, Canada and Great Britain, after all, the individual voter does not feel that the electoral victory of any one of the existing parties might jeopardise the country. Parliamentary institutions are capable of adapting themselves to new circumstances and of modifying themselves. In the long run, the masses do not wish to be without these means of self-expression.

\section{Solar Activity and Radio Transmission}

Recentuy, Dr. J. H. Dellinger, head of the radio section of the Bureau of Standards at Washington, suggested that a close watch should be kept to see whether there was a fade-out of radio transmissions at any time between October 21 and 25. He was led to make this suggestion by the discovery of severe fading occurring on March 20, May 12, July 6 and August 30, which indicate a 54-day cycle. Accord. ing to a report issued by Science Service, Washington, D.C., certain short wave-lengths were wiped out by eruptions of the sun for the single day October 24 . This fade-out sheds new light on the difficult problem of the connexion between radio transmission, sunspots and magnetic storms. Ordinary transmissions having wave-lengths approximately the same as those used in domestic broadcasting were not affected; but experimental radio transmission was completely wiped out, and the sending of commercial and amateur radiograms was greatly hampered.

The Bureau of Standards describes the occurrence on October 24 as a wiping out of radio transmission above a certain frequency. It is also stated that there was probably some eruption in the sun much more sudden than the growth of a sunspot, and that this abruptly changed the rate at which the sun 